\title{
IDENTIFICAÇÃO DO GRAU DE TURBULÊNCIA DO MERCADO CALÇADISTA: ANÁLISE POR MEIO DE UM SURVEY NOS PÓLOS DE FRANCA, BIRIGUI E JAÚ
}

\section{IDENTIFICATION OF THE FOOTWEAR MARKET TURBULENCE DEGREE: ANALYSIS THROUGH A SURVEY IN FRANCA, BIRIGUI AND JAÚ FOOTWEAR CLUSTERS}

\author{
Stella Jacyszyn Bachega ${ }^{1}$; Moacir Godinho Filho ${ }^{2}$ \\ ${ }^{1}$ Federal University of São Carlos - UFSCar - São Carlos - Brasil stella@dep.ufscar.br \\ ${ }^{2}$ Federal University of São Carlos - UFSCar - São Carlos - Brasil moacir@dep.ufscar.br
}

\begin{abstract}
Resumo
O padrão de concorrência, entre outras características do mercado calçadista, vem passando por mudanças expressivas nas últimas décadas, o que aumenta a turbulência do mercado. O presente artigo tem o objetivo de identificar os níveis de turbulência do mercado em empresas calçadistas dos pólos de Franca (calçados masculinos), Birigui (calçados infantis) e Jaú (calçados femininos), por meio do uso de uma adaptação dos trabalhos de Pine II (1993) e Sharifi e Zhang (1999) proposta por Godinho Filho e Fernandes (2006) e Godinho Filho (2004). O método de pesquisa utilizado foi a pesquisa de avaliação, também conhecida como survey. Foram entrevistadas 30 empresas, sendo que apenas 29 responderam o questionário. Dentre os resultados obtidos, observou-se que a maioria das empresas entrevistadas encontra-se no nível de turbulência médiaalta; também os fatores que mais contribuem para este nível de turbulência foram identificados. Este trabalho contribui para o setor calçadista, fornecendo informações sobre a turbulência do mercado e também se constitui em um impulsionador de pesquisas neste tema e neste setor da economia.
\end{abstract}

Palavras-chave: Turbulência do mercado, setor calçadista, survey.

\section{Introdução}

O mercado mundial se encontra cada vez mais competitivo e exigente. As empresas lidam com o aumento crescente no grau de exigências do mercado consumidor, disseminação da tecnologia, facilidade de acesso à informação e maior competição em níveis globais, o que conseqüentemente, aumenta a incerteza/turbulência do ambiente competitivo.

Os gestores, por conseguinte, necessitam se orientar sobre como competir em ambientes turbulentos para melhorar o desempenho organizacional. Pesquisas a respeito de turbulência do ambiente competitivo têm sugerido que as empresas adotem uma estrutura mais orgânica e menos 
centralizada em ambientes dinâmicos e incertos (HEWETT et al., 2003).

A turbulência do ambiente competitivo, portanto, refere-se à quantidade de mudança e à complexidade no ambiente de uma organização. Ao considerar as dimensões do ambiente organizacional (CHIAVENATO, 2001), o ambiente imediato deve ser examinado com atenção especial, uma vez que interfere diretamente na eficácia de uma organização. Dentre os componentes do ambiente imediato está o mercado, no qual o conhecimento de sua turbulência pode auxiliar as empresas no processo de tomada de decisões e, assim, adquirir/sustentar vantagens competitivas.

Autores como Moorman e Miner (1997), Slater e Narver (1994), e Jaworski e Kohli (1993) advogam que a turbulência do mercado é a taxa de mudança na composição de consumidores e suas preferências. Neste artigo, a análise de turbulência do mercado utiliza o grau de mudanças no ambiente de negócios da empresa, mudanças estas internas e externas, controláveis ou incontroláveis pela empresa, sendo medida por vinte e três fatores. Estes fatores foram listados por Godinho Filho (2004) ao adaptar os trabalhos de Pine II (1993) e Sharifi e Zhang (1999), dentre eles estão a natureza da demanda, a percepção do mercado quanto ao preço, qualidade e moda, e a complexidade na manufatura dos produtos.

O problema desta pesquisa baseia-se na premissa de que a identificação do nível de turbulência do mercado é necessária para as empresas adequarem as estratégias e os paradigmas de produção, conforme as necessidades do ambiente em que atuam, para assim sobreviverem e/ou prosperarem neste ambiente.

Um dos setores da economia que vem passando por transformações significativas no seu padrão de concorrência, entre outras características que afetam a turbulência do mercado, é o calçadista. Registrou-se uma perda relativa da importância do baixo custo salarial como determinante da competitividade do setor, em favor de fatores como qualidade, design e prazos de entrega. Como o calçado é um produto sujeito às variações da moda, a diferenciação do produto e a capacidade das empresas em captar os sinais de mercado são atributos que têm assumido papel cada vez mais importante na determinação da competitividade desse setor. Além disso, as mudanças tecnológicas são incrementais, pois setor se moderniza por etapas, dado a característica descontínua do processo de produção (GARCIA, 2001).

Nesse sentido, a presente pesquisa teve o objetivo de identificar os níveis de turbulência do mercado em empresas calçadistas dos pólos de Franca (calçados masculinos), Birigui (calçados infantis) e Jaú (calçados femininos), por meio do uso de uma adaptação dos trabalhos de Pine II (1993) e Sharifi e Zhang (1999) proposta por Godinho Filho e Fernandes (2006) e Godinho Filho (2004).

A estrutura do trabalho é a que segue: na próxima seção são abordadas algumas informações sobre a indústria calçadista e os pólos calçadistas, principalmente sobre os pólos estudados (Franca, 
Birigui e Jaú); na seção três encontra-se a metodologia da pesquisa, com algumas características dos pólos pesquisados; na quarta seção estão os resultados encontrados e na quinta seção estão as considerações finais.

\section{A indústria calçadista e os três pólos pesquisados}

Dentre os principais municípios e pólos calçadistas do país, conforme ABICALÇADOS (2005), destacam-se o pólo do Vale dos Sinos (Rio Grande do Sul - considerado o maior cluster de calçados do mundo), o município de São João Batista (Santa Catarina), os pólos de Nova Serrana, Belo Horizonte, Uberaba e Uberlândia (Minas Gerais), o município de Goianira (Goiás) no qual está em fase de implantação de um pólo calçadista, os pólos de Itapetinga, Jequié e Juazeiro (Bahia), os pólos de Santa Rita e Campina Grande (Paraíba), os pólos de Sobral da região de Fortaleza e da região do Cariri (Ceará), e os pólos de Franca, Birigui e Jaú (São Paulo), que constituem o objeto de pesquisa do presente artigo.

Os pólos calçadistas de Franca, Birigui e Jaú, localizados no estado de São Paulo, se destacam. Franca é o maior pólo produtor de calçados masculinos do Brasil, sendo integrado por 500 empresas de calçados que geram cerca de 22,6 mil empregos diretos. Cinqüenta países importam os calçados de Franca, resultando em US\$116,5 milhões arrecadados pelas organizações deste pólo em 2003. O pólo de Birigui é constituído por 166 empresas e é considerado o maior produtor de calçados infantis do país. Emprega cerca de 18 mil pessoas e exporta sete milhões de pares/ano. Jaú é um pólo especializado na produção de calçados femininos de couro, e apresenta um faturamento das exportações em 2003 de US\$ 11,5 milhões. Possui 182 empresas de calçados que geram 13 mil empregos diretos e cerca de sete mil indiretos (ABICALÇADOS, 2005).

\section{Metodologia de pesquisa}

Berto e Nakano $(2000 ; 1998)$ apontam os métodos de pesquisa mais utilizados em engenharia de produção, a saber: teórico-conceitual, experimental (CRESWELL, 1994), survey ou também conhecido como pesquisa de avaliação (FREITAS et al., 2000), pesquisa-ação (THIOLLENT, 1997) e estudo de caso (YIN, 1994).

O método de pesquisa survey foi escolhido para esta pesquisa devido ao intento de diagnosticar o comportamento do mercado, mais especificamente a turbulência do mercado, nos pólos de Birigui, Franca e Jaú. Foi utilizado o survey supervisionado, no qual o entrevistador faz as perguntas para garantir que cada informante responda a todas elas. Inicialmente, a pesquisa foi conduzida como um survey não-supervisionado, mais especificamente um e-mail survey. Devido à 
restrição de tempo e à não adesão inicial das empresas selecionadas ao e-mail survey, optou-se pelo survey supervisionado.

Constituíram objeto de estudo deste trabalho, empresas pertencentes ao setor calçadista do estado de São Paulo, mais especificamente dos pólos de Franca (calçados masculinos), Birigui (calçados infantis) e Jaú (calçados femininos). Tais empresas foram escolhidas por meio de amostragem probabilística e aleatória simples, de acordo com Babbie (1990).

A coleta de dados foi realizada por meio de entrevista utilizando-se um questionário estruturado, segundo Forza (2000). Tal coleta ocorreu no período de dezembro de 2005 a novembro de 2006, sendo a entrevista realizada pessoalmente em cada empresa pelo pesquisador. Foram entrevistados os funcionários de alto escalão (diretor ou gerente de produção/industrial), com a visão mais abrangente possível das empresas selecionadas. Além deles, no momento da entrevista contou-se com a colaboração de outros funcionários, dentre eles: proprietário, sócio da empresa, estilista, gerente de custos, diretor/gerente administrativos, gerente de exportação, gerente de tecnologia de informação, planejador e controlador da produção, gerente de administração de pessoal, procurador, e auxiliar de contabilidade.

Os dados quantitativos, coletados por meio dos questionários estruturados, foram tabulados e tratados estatisticamente utilizando-se o software SPSS (Statistical Package for the Social Science) v. 14.0 for Windows (2006).

A população de empresas calçadistas destas cidades foi obtida por meio dos respectivos sindicatos: SINDIFRANCA (Franca-SP), SINBI (Birigui-SP) e Sindicalçados-Jaú (Jaú-SP). Considerando apenas as empresas que possuem 100 ou mais funcionários (médio e grande porte), como convencionado para aplicação do questionário, foram identificadas 35 empresas no pólo de Franca que produzem calçados masculinos, 33 empresas no pólo de Birigui que fabricam calçados infantis e 16 empresas no pólo de Jaú que manufaturam calçados femininos. Esta preocupação em lidar apenas com empresas que fabricam os tipos de calçados que caracterizam cada pólo é justificada pela possibilidade de identificar se o grau de turbulência do mercado varia conforme o tipo de calçado fabricado.

O método utilizado para medir o grau de turbulência do mercado é uma adaptação dos trabalhos de Pine II (1993) e Sharifi e Zhang (1999) proposta por Godinho Filho e Fernandes (2006) e Godinho Filho (2004). Vinte e três fatores compõem a análise de turbulência, sendo que o comportamento destes fatores é levantado por meio de um questionário estruturado com escala Likert de onze pontos (0 a 10). Assim, o mercado apresenta maior turbulência quanto mais próximo do 10 .

Coletados os dados sobre estes fatores, realiza-se o somatório do comportamento dos 23 fatores (vide Quadro 1), ponderado ao grau da escala Likert atribuída, e compara-se tal valor com a 
seguinte escala de turbulência: i) turbulência baixa: de 0 a 45; ii) turbulência média-baixa: de 46 a 91; iii) turbulência média: de 92 a 137; iv) turbulência média-alta: de 138 a 183; v) turbulência alta: de 184 a 203.

\subsection{Algumas características dos pólos pesquisados}

A população de empresas com 100 ou mais funcionários é constituída de 84 empresas no total. No entanto, foi convencionado sortear 10 empresas de cada pólo (10 empresas em Jaú, 10 em Franca e 10 em Birigui) para compor a amostra estudada devido à limitação de tempo e recursos financeiros envolvidos. Logo, a amostra total foi de 30 empresas selecionadas, o que representa $35,7 \%$ da população de empresa com 100 ou mais funcionários. Dentre os 30 entrevistados apenas 29 responderam o questionário, sendo que a empresa não respondente pertence ao pólo de Franca, segundo a Tabela 1 .

Tabela 1 - Quantidade de empresas por pólo calçadista

\begin{tabular}{ccccc}
\hline Cidade & $\begin{array}{c}\text { Tipo de calçados } \\
\text { fabricados }\end{array}$ & $\begin{array}{c}\text { Número de empresas } \\
(\mathbf{1 0 0} \text { funcionários })\end{array}$ & $\begin{array}{c}\text { Empresas } \\
\text { visitadas }\end{array}$ & $\begin{array}{c}\text { Empresas } \\
\text { respondentes }\end{array}$ \\
\hline Birigui & Infantis & 33 & 10 & 10 \\
Franca & Masculinos & 35 & 10 & 9 \\
Jaú & Femininos & 16 & 10 & 10 \\
\hline Total & & 84 & 30 & 29 \\
\hline \multicolumn{5}{c}{ Fonte: Dados da pesquisa }
\end{tabular}

Como pode ser observado no Quadro 2, o número real de funcionários nas empresas entrevistadas variou de 60 a 2.200. Na fase de coleta de informações sobre as empresas para o processo de amostragem, as empresas selecionadas haviam informado que possuíam 100 ou mais funcionários, mas no momento da entrevista, cinco empresas afirmaram ter uma quantidade menor do que o previamente convencionado. Estas alegaram que, entre o período do processo de amostragem e da entrevista pessoal, houve demissão em massa de funcionários devido à crise no setor calçadista. Este ponto não foi considerado prejudicial ao trabalho, uma vez que essas empresas possuíam uma estrutura gerencial compatível com o intuito da pesquisa. O Quadro 2 aponta, também, a faixa de tempo em que as empresas estão no mercado, o tipo de empresa (limitada ou sociedade anônima), o tipo de capital (nacional ou internacional), e o número de trabalhadores alocados na produção. 
Quadro 2 - Alguns resultados da pesquisa

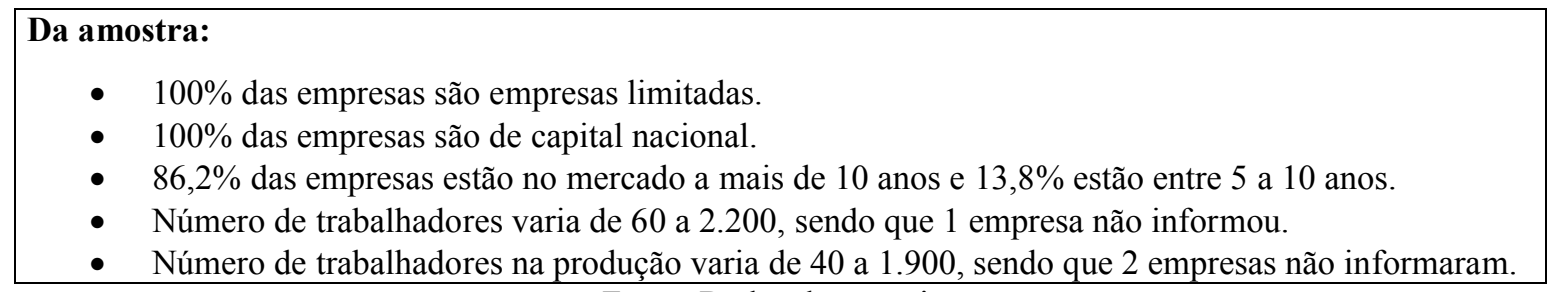

Fonte: Dados da pesquisa

Das 24 (vinte e quatro) empresas que informaram o faturamento em 2005, 29,2\% (7 empresas) possuíram faturamento até R \$ 6 milhões, 29,2\% (7 empresas) estão na faixa acima de R\$ 6 milhões até $\mathrm{R} \$ 20$ milhões, 25\% (6 empresas) estão na faixa acima de $\mathrm{R} \$ 244$ mil até $\mathrm{R} \$ 1,2$ milhões, 8,2\% (2 empresas) até R \$ 244 mil, 4,2\% (1 empresa) acima de 50 milhões, e 4,2\% (1 empresa) acima de R \$ 20 milhões até R\$ 50 milhões, como pode ser visto na Tabela 2.

Tabela 2 - Faixa de faturamento das empresas

\begin{tabular}{ccc}
\hline Faturamento & Faixa de faturamento durante 2005 & \% de empresas respondentes \\
\hline 1 & até R\$ 244 mil & 8,2 \\
2 & acima de R \$ 244 mil até R \$1,2 milhões & 25 \\
3 & até R \$ 6 milhões & 29,2 \\
4 & acima de R \$ 6 milhões até R \$ 20 milhões & 29,2 \\
5 & acima de R \$ 20 milhões até R\$ 50 milhões & 4,2 \\
6 & acima de 50 milhões & 4,2 \\
\hline
\end{tabular}

Fonte: Dados da pesquisa

\section{Resultados}

Os resultados da pesquisa apontam que nos pólos calçadistas de Franca, Birigui e Jaú, as empresas entrevistadas estão inseridas em um ambiente muito dinâmico e complexo. A maioria dos níveis de turbulência encontrada foi de médio (92 a 137) a médio-alto (138 a 183). Somente no pólo de Jaú foi encontrado um caso de turbulência média-baixa (46 a 91).

No pólo de Franca, 66,7\% dos 9 respondentes encontram-se no nível de turbulência médiaalta (138 a 183) e 33,3\% encontra-se em turbulência média (92 a 137). Em Birigui, tanto as faixas de turbulência média e média-alta aparecem em 50\% das 10 empresas entrevistadas. Já no pólo de Jaú, 50\% dos 10 entrevistados estão na faixa de turbulência média-alta, $40 \%$ em situação de turbulência média e 10\% em turbulência média-baixa. O Quadro 3 apresenta as percentagens e as respectivas freqüências (em parêntesis) dos resultados obtidos, quanto às faixas de turbulência, em cada pólo estudado. 
Quadro 3 - Graus de turbulência obtidos na pesquisa

\begin{tabular}{|l|r|r|r|}
\hline $\begin{array}{c}\text { Graus de turbulência / } \\
\text { Pólos }\end{array}$ & \multicolumn{1}{c|}{ Birigui } & \multicolumn{1}{c|}{ Franca } & \multicolumn{1}{c|}{ Jaú } \\
\hline De 0 a 45 (baixa) & $0 \%(0)$ & $0 \%(0)$ & $0 \%(0)$ \\
\hline De 46 a 91 (média-baixa) & $0 \%(0)$ & $0 \%(0)$ & $10 \%(1)$ \\
\hline De 92 a 137 (média) & $50 \%(5)$ & $33,3 \%(3)$ & $40 \%(4)$ \\
\hline De 138 a 183 (média-alta) & $50 \%(5)$ & $66,7 \%(6)$ & $50 \%(5)$ \\
\hline De 184 a 203 (alta) & $0 \%(0)$ & $0 \%(0)$ & $0 \%(0)$ \\
\hline Total de citações & $100 \%(10)$ & $100 \%(9)$ & $100 \%(10)$ \\
\hline
\end{tabular}

Pode-se observar, também, que em Franca, pólo caracterizado pela produção de calçados masculinos, houve maior freqüência de empresas no nível de turbulência médio-alto, ou seja, há possível tendência do mercado de calçados masculinos estar mais turbulento do que o mercado de calçados femininos e infantis. Este fato deve ser confirmado por meio de um survey que permita generalizações.

O Quadro 4 apresenta os graus de turbulência encontrados em cada empresa entrevistada, detalhados por pólo calçadista estudado. Pode-se observar que, em Birigui, os graus variam de no mínimo 119 a um máximo de 164. Em Jaú o mínimo obtido foi 55 e o máximo 159, e em Franca, o mínimo foi 129 e o máximo 165. Portanto, a empresa com o maior grau de turbulência encontrada nesta pesquisa foi em Franca (calçados masculinos) e a empresa com o menor nível de turbulência foi em Jaú (calçados femininos).

Quadro 4 - Graus de turbulência detalhados por empresa/pólo

\begin{tabular}{|c|r|r|r|}
\hline \multirow{2}{*}{ Empresas } & \multicolumn{3}{|c|}{ Graus de Turbulência } \\
\cline { 2 - 4 } & Birigui & Jaú & Franca \\
\hline 1 & 119 & 55 & 129 \\
\hline 2 & 126 & 100 & 129 \\
\hline 3 & 129 & 113 & 136 \\
\hline 4 & 135 & 118 & 138 \\
\hline 5 & 137 & 135 & 140 \\
\hline 6 & 139 & 138 & 141 \\
\hline 7 & 143 & 138 & 151 \\
\hline 8 & 150 & 151 & 156 \\
\hline 9 & 160 & 156 & 165 \\
\hline 10 & 164 & 159 & - \\
\hline
\end{tabular}

Analisando os resultados obtidos nos três pólos conjuntamente, dos 29 respondentes, cerca de 55,2\% das empresas se encontram em um nível de turbulência média-alta (138 a 183), 41,4\% na faixa de turbulência média (92 a 137), e 3,4\% estão no nível de turbulência média-baixa (46 a 91), conforme a Figura 1. Este fato assinala uma possível tendência de que a turbulência média-alta seja uma situação predominante no setor calçadista do estado de São Paulo. 
Figura 1 - Gráfico das percentagens dos graus de turbulência encontrados nas empresas entrevistadas

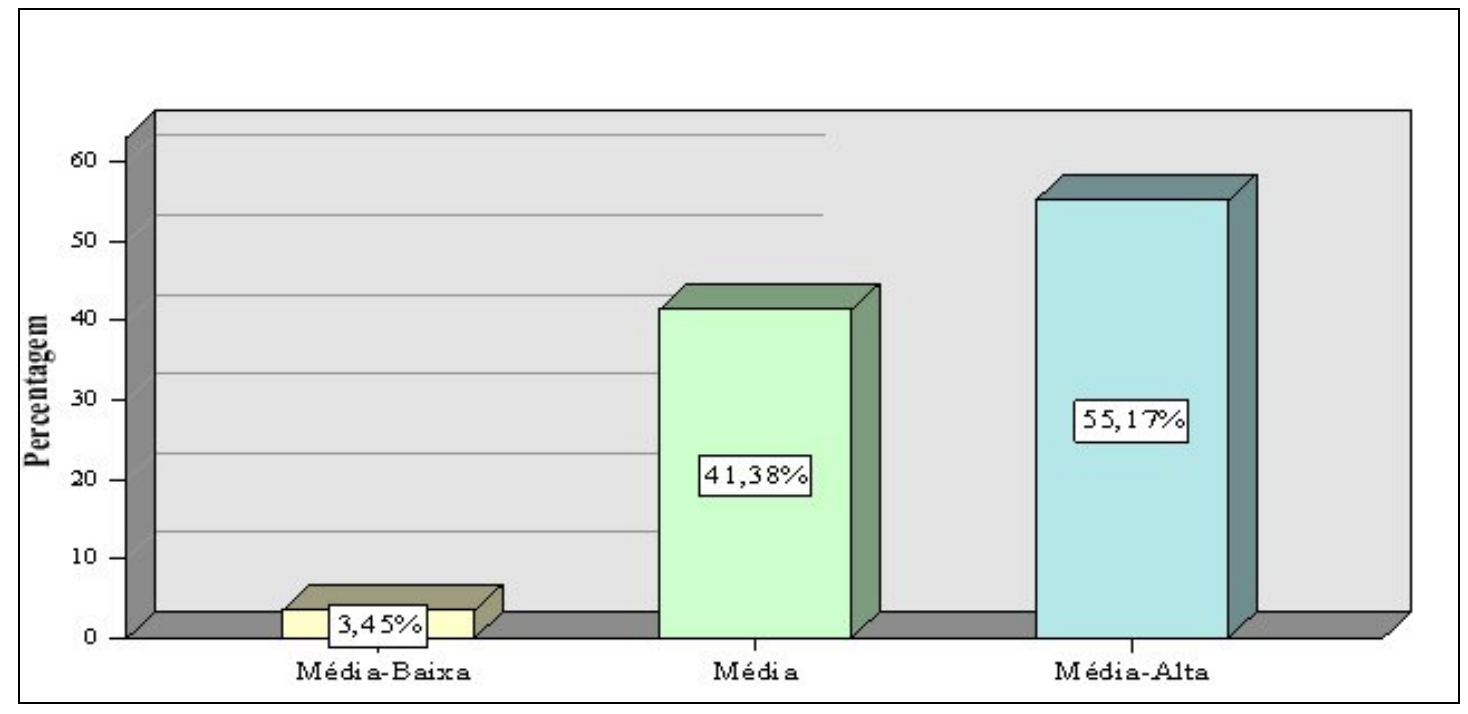

Fonte: Dados da pesquisa

O Quadro 5 apresenta os fatores que influenciam a turbulência do mercado, classificados de acordo com a escala Likert disponibilizada no questionário aplicado às empresas entrevistadas, seguidos das respectivas percentagens de resposta. $\mathrm{Na}$ escala, a faixa de 0 a 3 caracteriza baixa influência, de 4 a 6 média influência e de 7 a 10 alta influência. Dentre os 29 respondentes, 82,8\% citaram os fatores 'Mercado com grande percepção na qualidade' e 'Mercado com grande percepção na moda' como fatores que proporcionam alta influência no mercado em que atuam, entre outros fatores. No entanto, dentre os fatores identificados como de média influência, 65,5\% dos respondentes citaram os 'Tipos de produtos fornecidos pela empresa' e a 'Introdução de tecnologias completamente novas'. Já o único fator que obteve a maioria de citações como baixa influência foi a 'Facilidade na identificação das necessidades dos clientes'. Cabe ressaltar que o fator 'Poder de resposta dos concorrentes' obteve a mesma freqüência de citações nas as faixas de 7 a 10 e de 4 a 6 da escala Likert, o caracterizando como de alta e de média influência.

\section{Considerações finais}

Foram identificados, por meio do survey, os níveis de turbulência do mercado calçadista nos pólos de Franca, Birigui e Jaú, conforme a adaptação dos trabalhos de Pine II (1993) e Sharifi e Zhang (1999) proposta por Godinho Filho e Fernandes (2006) e Godinho Filho (2004), logo, o objetivo almejado na pesquisa foi atingido. Os dados coletados permitiram verificar que o mercado nos pólos calçadistas de Franca, Birigui e Jaú encontra-se com predominância do nível de turbulência média-alta, no qual, considerando os três pólos conjuntamente, $55,2 \%$ dos 29 respondentes encontram-se neste nível de turbulência.

Portanto, os fatores citados como de alta influência na turbulência do mercado necessitam de 
maior atenção por parte das empresas, caso estas desejem sobreviver/prosperar neste ambiente turbulento. Assim, as empresas calçadistas ao delinearem suas estratégias corporativas, de unidades de negócio e funcionais, deveriam despender grande parte do tempo deste processo analisando os fatores qualidade, moda, taxa de mudança nas necessidade dos clientes, preço, competitividade, serviços pré e pós-vendas, ciclos econômicos, fornecedores, concorrência e natureza da demanda. Cabe ressaltar que no processo de formulação de estratégias é necessário considerar uma gama de fatores, além desses apresentados no artigo, para análise de ambientes/cenários, tomando de base o método de análise de ambiente SWOT (Strengths, Weaknesses, Opportunities, Threats ou Forças, Fraquezas, Oportunidades e Ameaças).

Quadro 5 - Percentagem dos fatores que influenciam a turbulência do mercado

\begin{tabular}{|c|c|c|}
\hline $\begin{array}{c}\text { Faixa de } \\
\text { influência }\end{array}$ & Fatores que influenciam a turbulência & $\begin{array}{l}\text { Percentagem } \\
\text { de respostas }\end{array}$ \\
\hline \multirow{10}{*}{ Alta (7 a 10) } & Mercado com grande percepção na qualidade & $82,8 \%$ \\
\hline & Mercado com grande percepção na moda & $82,8 \%$ \\
\hline & Taxa de mudança nas necessidades dos clientes & $62,1 \%$ \\
\hline & Mercado com grande percepção nos preço & $62,1 \%$ \\
\hline & Intensidade competitiva & $62,1 \%$ \\
\hline & Nível do serviço pré e pós-vendas & $58,6 \%$ \\
\hline & Grau de influência de ciclos econômicos para a empresa & $55,2 \%$ \\
\hline & Confiabilidade nos fornecedores & $44,8 \%$ \\
\hline & Poder de resposta dos concorrentes & $44,8 \%$ \\
\hline & Natureza da demanda & $48,3 \%$ \\
\hline \multirow{13}{*}{ Média (4 a 6) } & Tipos de produtos fornecidos pela empresa & $65,5 \%$ \\
\hline & Introdução de tecnologias completamente novas & $65,5 \%$ \\
\hline & Estrutura competitiva & $62,1 \%$ \\
\hline & Taxa de mudança tecnológica no produto & $62,1 \%$ \\
\hline & Poder de compra dos clientes & $58,6 \%$ \\
\hline & Estabilidade e previsibilidade da demanda & $51,7 \%$ \\
\hline & Tamanho e previsibilidade do ciclo dos produtos & $51,7 \%$ \\
\hline & Nível de saturação do mercado & $48,3 \%$ \\
\hline & Complexidade no projeto dos produtos da empresa & $48,3 \%$ \\
\hline & Vulnerabilidade a produtos substitutos & $44,8 \%$ \\
\hline & Complexidade na manufatura dos produtos & $44,8 \%$ \\
\hline & Poder de resposta dos concorrentes & $44,8 \%$ \\
\hline & Pressões ambientais & $41,4 \%$ \\
\hline Baixa (0 - 3) & Facilidade na identificação das necessidades dos clientes & $55,2 \%$ \\
\hline
\end{tabular}

Fonte: Dados da pesquisa

A identificação dos níveis de turbulência é importante, também, para auxiliar a empresa a adequar o paradigma de produção utilizado (Manufatura em Massa Atual, Manufatura Enxuta, Manufatura Responsiva, Customização em Massa e Manufatura Ágil), conforme as necessidades do ambiente em que a empresa atua. Tal visão é defendida nos trabalhos de Bachega (2006), Godinho Filho e Fernandes (2006; 2005) e Godinho Filho (2004).

Este trabalho contribui para o setor calçadista, mais especificamente para as empresas dos 
pólos de Franca, Birigui e Jaú, pois as informações aqui apresentadas são importantes para um setor que se encontra em crise, como é a realidade do setor coureiro-calçadista. Além disso, se constitui em um impulsionador de pesquisas neste tema e neste setor da economia.

Quanto as proposta de pesquisas futuras, sugere-se que o método seja aplicado nos demais setores da economia. Também há a possibilidade de novas aplicações em pesquisas de avaliação no mesmo setor, com intuito de comparar outros pólos ou até mesmo analisar o setor em âmbitos nacional/internacional, com aquisição de resultados que permitam generalizações.

\title{
Agradecimento
}

À Coordenação de Aperfeiçoamento de Pessoal de Nível Superior (CAPES), pela concessão de bolsa, e à Fundação de Amparo à Pesquisa do Estado de São Paulo (FAPESP) pelo suporte financeiro concedido (projeto $\mathrm{n}^{\mathrm{o}} 05 / 56498-0$ ) durante o desenvolvimento deste trabalho.

\begin{abstract}
The pattern of competition, among other characteristics of the footwear market, has been going through some expressive changes in the last decades, which increases the market turbulences. The present paper aims to identify the turbulence levels of the market in footwear companies in the clusters of Franca (male footwear), Birigui (children footwear), and Jaú (female footwear), through the use of an adaptation of Pine II (1993), Sharifi and Zhang (1999) works, proposed by Godinho Filho and Fernandes (2006) and Godinho Filho (2004). The research method used was the survey. Thirty companies were interviewed, but only 29 (twenty nine) answered the questionnaire. Among the obtained results, it was observed that most of the companies interviewed are in a medium-high level of turbulence; also, that the factors which contribute the most for this level of turbulence were identified. This paper contributes to the footwear sector, furnishing information about the market turbulence and also it constitutes itself into a drive on for researches in this theme and in this economy sector.
\end{abstract}

Key-words: market turbulence, footwear sector, survey.

\section{Referências \\ ABICALÇADOS. Associação Brasileira das Indústrias de Calçados. 2005. Disponível em: <http://www.abicalcados.com.br>. Acesso em: 14 abr. 2005.}

BABBIE, E. Survey research methods. Wadsworth, Belmont, CA. 1990. 395 p.

BACHEGA, S. J. Paradigmas Estratégicos de Gestão da Manufatura nos pólos de Franca, Birigui e Jaú: análise por meio de um survey. 2006. 196 p. Dissertação (Mestrado em Engenharia de Produção) - Universidade Federal de São Carlos, São Carlos.

BERTO, R. M. V. S.; NAKANO, D. N. A produção científica nos anais do encontro nacional de engenharia de produção: um levantamento dos métodos e tipos de pesquisa. Produção, v. 9, nº 2, p. 65-75, jul. 2000.

BERTO, R. M. V. S.; NAKANO, D. N. Metodologia da pesquisa e a engenharia de produção. In: XVIII Encontro Nacional de Engenharia de Produção (ENEGEP) e IV International Congress of Industrial Engineering (ICIE), 1998, Niterói, RJ. Anais...Niterói: UFF/ABEPRO, out. 1998. 1 CD-ROM.

CHIAVEnAtO, I. Teoria Geral da Administração. v.1. Rio de Janeiro: Campus, 2001, 695 p. 
CRESWELL, J. W. Research design: qualitative \& quantitative approaches. London: Sage, 1994. 248 p.

FORZA, C. Survey research in operations management: a process-based perspective. International Journal of Operations \& Production Management, v.22, n.2, pp. 152-194, 2002.

cross ${ }^{\text {ref }}$

FREITAS, H.; OLIVEIRA, M.; SACCOL, A. Z.; MOSCAROLA, J. O método de pesquisa survey. Revista de Administração, v.35, n.3, pp.105-112, 2000.

GARCIA, R. C. Vantagens competitivas de empresas em aglomerações industriais: um estudo aplicado à indústria brasileira de calçados e sua inserção nas cadeias produtivas globais. 2001. Tese (Doutorado) - Instituto de Economia, Universidade Estadual de Campinas, Campinas.

GODINHO FILHO, M. Paradigmas Estratégicos de Gestão da Manufatura: configuração, relações com o planejamento e controle da produção e estudo exploratório na indústria de calçados. 2004. 267 p. Tese (Doutorado em Engenharia de Produção) - Universidade Federal de São Carlos, São Carlos.

GODINHO FILHO, M.; FERNANDES, F. C. F. Paradigmas Estratégicos de Gestão da Manufatura: identificação, prescrição e estudo de casos na indústria de calçados. Artigo aprovado para publicação na RAUSP em 2006.

GODINHO FILHO, M; FERNANDES, F. C. F. Paradigmas Estratégicos de Gestão da Manufatura (PEGEMs): elementos chave e modelo conceitual. Gestão \& Produção, v. 12, n.3, set-dez. 2005. p. 333-345.

HEWETT, K.; ROTH, M. S.; ROTH, K. Conditions influencing headquarters and foreign subsidiary roles in marketing activities and their effects on performance. Journal of International Business Studies, 34, pp.567-585, 2003.

cross ${ }^{\text {ref }}$

JAWORSKI, B. J.; KOHLI, A. Market orientation: antecedents and consequences, Journal of Marketing, 57, pp.5370, 1993.

cross ref

MOORMAN, C.; MINER, A. S. The impact of organizational memory on new product performance and creativity, Journal of Marketing Research, 34, pp. 91-106, 1997.

cross ref

PINE II, B. J. Mass customization: the new frontier in business competition, Harvard Business School Press, Boston, Massachussets, 1993. 368 p.

SHARIFI, H.; ZHANG, Z. A Methodology for achieving agility in manufacturing organizations: an introduction. International Journal of Production Economics, v. 62, pp. 7 - 22, 1999.

cross ref

SLATER, S. F.; NARVER, J. C. Does competitive environment moderate the market orientation-performance relationship?, Journal of Marketing, 58(1), pp. 46-55, 1994.

cross ref

SPSS. Statistical Package for the Social Science, v. 14.0 for Windows. Free trial version. Disponível em: $<$ http://www.spss.com>. Acesso em: 07 de ago. de 2006.

THIOLLENT, M. J. M. Pesquisa-ação em organizações. São Paulo: Atlas, 1997.

YIN, R. K. Case study research: design and methods. Newbury Park, California: Sage Publications, 1994. 166p.

\section{Dados dos autores:}

Nome completo: Stella Jacyszyn Bachega

Filiação institucional: Universidade Federal de São Carlos - UFSCar 
Departamento: Engenharia de Produção

Função ou cargo ocupado: Doutoranda

Endereço completo: Rua Episcopal, 2542/14, Centro, São Carlos, São Paulo, Brasil,

CEP: $13.560-580$

Telefones para contato: (16) 3501-5386

E-mail: stella@dep.ufscar.br

Nome completo: Moacir Godinho Filho

Filiação institucional: Universidade Federal de São Carlos

Departamento: Engenharia de Produção

Função ou cargo ocupado: Professor Adjunto

Endereço completo: Rod. Washington Luís, Km 235, São Carlos, São Paulo, Brasil,

CEP: $13.565-905$

Telefones: (16) 3351-8236 R.9207

E-mail: moacir@dep.ufscar.br

Recebido para publicação em: 20/11/2007

Aceito para publicação em: 04/12/2007 